\title{
Gender Prediction from the Primary Fingerprint Pattern: A Study among Medical Students in Ambrose Alli University, Ekpoma
}

\author{
Anyanwu Luke Chukwumah* \\ Department of Anatomy, Faculty of Basic Medical Sciences, Ekpoma, Nigeria \\ *Corresponding author: Anyanwu Luke Chukwuma, Department of Anatomy, Faculty of Basic Medical Sciences, College \\ of Medicine, Ambrose Alli University, Ekpoma, Nigeria
}

ARTICLE INFO

Received: 彗 July 13, 2020

Published: 蔧 July 21, 2020

Citation: Anyanwu Luke Chukwumah. Gender Prediction from the Primary Fingerprint Pattern: A Study among Medical Students in Ambrose Alli University, Ekpoma. Biomed J Sci \& Tech Res 29(1)2020. BJSTR. MS.ID.004739.

Keywords: Dermatoglyphics; Fingerprints; Medical Students

\section{ABSTRACT}

Many studies on dermatoglyphics patterns have proven useful for identification and disease prognosis but there are only few studies among Africans and the Nigerian population in particular. Toward this purpose, this study is aimed to investigate the prevalent fingerprint patterns of healthy population among Medical Students in Ambrose Alli University, Ekpoma-Nigeria and the association between genders. The ink method was used to collect prints from the right and left fingers of 200 (100 each of females and males) medical students who gave consent and has no deformation of the digits. The data were analyzed for descriptive statistics after putting data into statistical package for social sciences (version 20). The most prevalent finger prints were the loop $(n=886)$ and whorl $(n=776)$. The different primary fingerprints were more prevalent in the left hand compared to the right hand but the different was not significant $(\mathrm{p}=0.698)$. There was a non-significant higher $(\mathrm{p}=0.391)$ whorl fingerprint pattern in the male $(51.5 \%)$ but the loop $(52.0 \%)$ and arches $(51.0 \%)$ patterns in the female. The loop $(54.7 \%)$ and arches $(52.4 \%)$ patterns were more in the female with respect to their right hand while male represented more in the whorl (53\%) and loop (51\%) in the left hand. This study showed that the loop and whorl types of fingerprints are the most prevalent among medical students and there is no variation in the fingerprints patterns of male and female medical students. By implication, the primary fingerprints pattern may not be a useful prediction tool of gender classification of medical students.

\section{Introduction}

Identification of humans is a necessity for personal, social and legal reasons [1] and involves functional or psychic, normal or pathological characteristics that may define the individual [2]. The methods of identification according to Vahanwala [3] and Bansal et al. [4] include anthropometry, dactyloscopy, fingerprinting, sex determination, estimation of age, measurement of height, post-mortem reports, differentiation by blood groups as well as race, handwriting, skin texture and garments. The most important of these parameters is the fingerprints which often provide the positive identification of an individual or suspect because it is unique, durable and permanent [4]. Fingerprints are impressions of the unique characteristic mark or pattern curved lines of skin at the end of a finger that is left on a surface or made by pressing an inked finger onto paper. Some of the earliest works on the use of fingerprints for personal identification were carried out in India so many years ago $[5,6]$.

Human fingerprint is characterized by various types of ridge patterns classified as "Loop", "Whorl" or "Arche", with each having unique characteristics with respect to a reference point called a Triradius [7] and constitute 60-65, 30-35 and $5 \%$ of all fingerprints, respectively [8]. The factors affecting the development of fingerprints towards a regular shape (such as size, degree of stoutness, growth rate of bone and thickness of subcutaneous fat) eventually result in the diversity of fingerprints [9]. Fingerprint 
is genotypically determined and it is affected by intrauterine environment in the first trimester of pregnancy though they are characterized by alternating strips of raised frictional ridge and depressed grooves on the fingertips [8]. The characteristic patterns of epidermal ridges are differentiated in their definitive forms during the third and fourth months of fetal life [10] and they remain unchanged from birth till death [11]. Dermatoglyphics; the scientific study of epidermal ridge patterns of the skin of the fingers, palms, toes, and soles [12] have been widely employed in areas as anthropology, genetics and evolutionary studies in characterizing populations, analyzing the nature and origin of human variability, population structure assessment, and the microdifferentiation among populations [12-15]. Although many studies on dermatoglyphics patterns have been conducted in different parts of the world, there are only limited studies carried out so far in Africa [16-19]. Study of finger prints among medical students in Nigeria is limited and hence the focus of this study.

\section{Materials and Methods}

\section{Study Area/Population}

This study was conducted in the Medical College of Ambrose Alli University in Ekpoma, Nigeria. Ekpoma is a town in Edo State and serves as the administrative headquarters of the Esan West Local Government Area. The area lies on the geographical coordinate of latitude $6^{\circ} 45^{\prime} \mathrm{N} 6^{\circ} 08^{\prime} \mathrm{E}$ and occupies a land mass of $502 \mathrm{~km}$ sq. The study populations are medical students of the College of Medicine, Ambrose Alli University, Ekpoma, Nigeria.

\section{Sample Size Determination}

Using a prevalence rate of $14 \%$, sample size was determined using the formula by Araoye [20] and this gave a 185 respondent but was approximated to 200 for a higher precision. This was divided into both sex and comprises of 100 each of male and female.

\section{Ethical Consideration}

Ethical permission for this study was sought and obtained from Ambrose Alli University Research and Ethics Committee and informed consent of participating students were obtained. Data collection was in compliance with the Declaration of the Right of the subject as documented in the Helsinki declaration [21].

\section{Inclusion Criteria}

Medical students in their 100 to 500 levels of the College of Medicine who gave consent and had no loss/deformation of the limbs or digits were included in this study.

\section{Sampling Techniques}

The sampling techniques that will be used in this study for selection of subjects will be the purposive sampling technique where participants will be chosen based on characteristics of a population and the purpose of the study. Two hundred Students of College of Medicine Ambrose Alli University, were recruited for this study.

\section{Instrument for Data Collection}

Using self-structured research questionnaires, social demographic profile were collected. The Indian ink method by Cummins [22] was used to collect digital prints on fingers. Briefly, the subjects were asked to clean their hands with soap and water and allowed to dry but with some moisture. Requisite amount of ink was rubbed on the stamp pad and was uniformly spread. The left hand of the subject was placed on the stamp pad which is placed on a hard surface. The fingers printed the tip of the fingers was rolled from the radial to ulnar side to include all the patterns. The same procedure was repeated for the right hand. The ink removed from the subject hands with the aid of about 1\% HCL which will neutralize the ink. The prints were analyzed and classified with the help of a hand lens.

\section{Data Analysis}

Data obtained were coded and entered into Statistical Package for Social Scientists (SPSS) version 20.0 software spread sheet and then analyzed. Test of significance was done using the chi-square. All tests were at $95 \%$ confidence level.

\section{Results}

Table 1 shows the socio-demographic characteristics of the studied participants. Majority of the participants were within the ages of 18 to 20 years (46.5\%) and $42 \%$ of them were from the Esan ethnic group. They were mainly Christian (88.5\%). Figure 1 shows the distribution of the different fingerprints among the studied participants. There were more loop $(n=886)$ followed by whorl $(\mathrm{n}=776)$ while the arche $(\mathrm{n}=306)$ was least represented among the three primary fingerprints. Table 2 shows the relationship fingerprint patterns distribution between left and right hand. The whorl, loop and arches pattern of fingerprints were more represented in the left hand (50.5\%,52.5\% and 51.5\% respectively) compared to the right hand (49.5\%, $47 \%$ and $48.5 \%$ respectively). The different in distribution between the left and right hands was not significant $(\mathrm{p}=0.698)$.

Table 1: Socio demographic characteristics of the studied participants.

\begin{tabular}{|c|c|c|c|}
\hline \multirow{4}{*}{ Age } & $18-20$ & Frequency & Percentage (\%) \\
\cline { 2 - 4 } & $21-23$ & 93 & 46.5 \\
\cline { 2 - 4 } & 24 above & 85 & 42.5 \\
\hline \multirow{4}{*}{ Ethnicity } & Esan & 84 & 11 \\
\cline { 2 - 4 } & Bini & 43 & 42 \\
\cline { 2 - 4 } & Others & 73 & 21.5 \\
\hline \multirow{5}{*}{ Religion } & Christian & 177 & 36.5 \\
\cline { 2 - 4 } & Muslim & 9 & 88.5 \\
\cline { 2 - 4 } & Traditional & 4 & 2 \\
\cline { 2 - 4 } & Others & 10 & 5 \\
\hline
\end{tabular}


Table 2: Relationship of fingerprint patterns distribution between Left and Right hands.

\begin{tabular}{|c|c|c|c|}
\hline & Whorl N (\%) & Loop N (\%) & Arches N (\%) \\
\hline Left & $392(50.5)$ & $466(52.5)$ & $174(51.5)$ \\
\hline Right & $384(49.5)$ & $420(47)$ & 0.719 \\
Df:2 & $164(48.5)$ & 0.698 \\
\hline
\end{tabular}

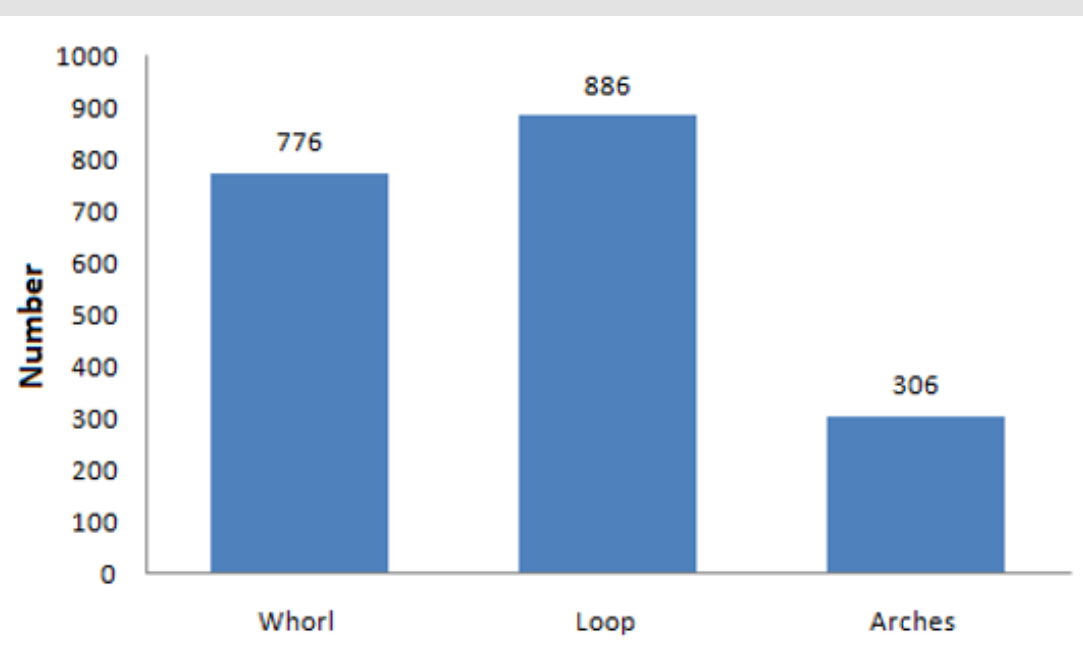

Figure 1: Distribution of the different types of fingerprints.

Table 3 shows the relationship between gender and finger print patterns. The whorl finger print pattern was common in the male (51.5\%) while the loop and arches patterns were more common in the female (52.0\% and $51.0 \%$ respectively). However, the difference in distributions of these fingerprints between gender were not significant $(p=0.391)$. Table 4 shows the relationship between gender and fingerprint patterns distribution in right and left hands.
In the right hand, the whorl pattern was $50 \%$ in both genders while females represented more in the loop (54.7\%) and arches (52.4\%) patterns. However, in the left hand, male represented more in the whorl (53\%) and loop (51\%) while female presented more in the arches pattern (55\%). Statistically, there were no significant difference in the pattern of fingerprint distribution in the right $(p=0.402)$ and left hand $(p=0.192)$ between gender.

Table 3: Relationship between gender and finger print patterns.

\begin{tabular}{|c|c|c|c|c|}
\hline & Whorl N (\%) & Loop N (\%) & Arches N (\%) & Stat \\
\cline { 1 - 4 } Male & $400(51.5)$ & $428(48)$ & $150(49.0)$ & X $=1.876$ \\
Females & $376(48.5)$ & $458(52)$ & $156(51.0)$ & Df:2 \\
P=0.391 \\
\hline
\end{tabular}

Table 4: Relationship between gender and fingerprint patterns distribution in right and left hands.

\begin{tabular}{|c|c|c|c|c|c|}
\hline & & Whorl n (\%) & Loop n (\%) & Arches n (\%) & Test Stat \\
\hline \multirow[b]{2}{*}{ Right hand } & Male & $192(50)$ & $190(46.6)$ & $78(47.5)$ & \multirow{2}{*}{$\begin{array}{c}X=1.824 \\
D f: 2 \\
P=0.402\end{array}$} \\
\hline & Females & $192(50)$ & $230(54.7)$ & $86(52.4)$ & \\
\hline \multirow{2}{*}{ Left hand } & Male & $208(53)$ & $238(51)$ & $78(44.8)$ & \multirow{2}{*}{$\begin{array}{c}X=3.299 \\
D f: 2 \\
P=0.192\end{array}$} \\
\hline & Females & $184(46.9)$ & $228(48.9)$ & $96(55)$ & \\
\hline
\end{tabular}

\section{Discussion}

The dermatoglyphic science is based on facts that the ridges are slightly different for different fingers, individuals (even monozygotic twins) and are permanent throughout life after the 21st week intrauterine life [23] and these qualified the ridges as identification tool. This study demonstrated the loop and whorl patterns to be the most prevalent fingerprints among medical students either on the right or left hand. This is consistent with other studies done in Nigeria that observed loop as the highest frequency, followed by whorl and then arch pattern [24,25]. Studies in other parts of Africa have reported similar dermatoglyphic patterns but with variations in percentages [26,27]. In fact, it is documented that 60-65\%, 30$35 \%$ and $5 \%$ constitute of the loop, whorl and arches fingerprints respectively by Wijerathne et al. [8] This finding correlates with other population studies among students of Delta state University, 
Abraka, Nigeria [2] suggesting that the current results could be a reflection of the prevalence fingerprints in the population of Nigeria.

In the current study, males have higher percentage of whorl while females have higher pencentage of loop and arches but there was no relationship between gender and fingerprints pattern of the medical students. This agrees with the study by Prateek and Keerthi [28] among 200 medical students of Kasturba Medical College, Mangalore, who reported the frequency of loops and arches is greater in females as compared to a higher frequency of whorls in males. The study by Eboh [2] reported males to have higher percentage of arches (51.4\%) while female recorded higher percentages of loop (52.9\%) and whorl (51.5\%) among students of Delta state University, Abraka, Nigeria. In accordance with the observed non-significant association between gender and fingerprints patterns of Medical students of Ambrose Alli University in Ekpoma, both Eboh [2] and Odokuma et al. [29] have reported no significant association between gender and the five fingerprints of each hand and thumb print patterns respectively. According to Adamu [30] in identity determination, adequate and reliable knowledge of sex with certainty reduces the process of identification by $60 \%$ using fingerprint ridge counts and density. However, Iso-Iso et al. [31] documented that the thumbprint ridge count shows gender dimorphism in the Nigerian population.

\section{Conclusion}

In conclusion, this study showed the loop and whorl to be the most prevalence fingerprints no association of these fingerprints with gender among medical students of Ambrose Alli University in Ekpoma. Judging by these findings, it can be deduced that the prediction of medical students' gender may not be possible from the distribution of the primary fingerprint pattern.

\section{References}

1. Limson KS, Julian R (2004) Computerized recording of the palatal rugae pattern and an evaluation of its application in forensic identification. Forensic Odontostomatol 22(1): 1-4

2. Eboh DE (2013) Fingerprint patterns in relation to gender and blood group among students of Delta State University, Abraka, Nigeria. J Exp Clin Anat 12(2): 82-86.

3. Vahanwala S (2005) Study of lip-prints as an aid for sex determination Med Leg Update 5(3): 93-98.

4. Bansal HD, Hansi D, Badiye AD, Kapoor NS (2014) Distribution of Fingerprint Patterns in an Indian Population. Malaysian Journal of Forensic Sciences 5(2): 18-21.

5. Herschel WJ (1916) The Origin of Finger-Printing. Oxford University Press, Oxford 268(1916).

6. Herschel WJ (1880) Skin furrows of the hand. Nature 23(578): 76.

7. Gutierez SB, Lucenario JS, Yebes MT (2012) Dermatoglyphic Studies among the Dumagat-Remontado Tribal Population of the Philippines. Journal of Anthropology pp. 20-26.

8. Wijerathne BTB, Rathnayake GK, Adikari SC, Amarasinghe S, Abhayarathna PL, et al. (2013) Sexual dimorphism in digital dermatoglyphic traits among Sinhalese people in Sri Lanka. Journal of Physiological Anthropology 32(1): 27.

9. Yang X, Xiaojun J, Yixuan Z, Hui L (2016) Genetics Rules for the Dermatoglyphics of Human Fingertips and their role in Spouse Selection: A preliminary Study. Sprin Plus 5(1): 1396.

10. Cummins H, Kennedy RW (1940) Physiological Examination of visual organ and of the cutaneous system. Am J Crim Law Criminol 31: 343-356.

11. Vij K (2005) Textbook of Forensic Medicine and Toxicology. $3^{\text {rd }}$ (edn.). Elsevier, New Delhi, India, pp. 89-91.

12. Cummins H (1926) Palmar and Plantar Epidermal Ridge Configuration (Dermatoglyphics) in Europeans and Americans. Am J Phys Anthrop 9(4): 471-502.

13. Meier RJ (1980) Anthropological Dermatoglyphics: A Review. American Journal of Physical Anthropology 23(1S): 147-178.

14. Durham NM, Plato CC (1990) Trends in dermatoglyphic research. $1^{\text {st }}$ (Edn). Netherlands: Springer Netherlands pp. 724.

15. Segura-Wang M, Barrantes R (2009) Dermatoglyphic traits of six Chibcha-speaking Amerindians of Costa Rica, and an assessment of the genetic affinities among populations. Revista de Biologia Tropical 57(SUPPL 1): 357-369.

16. Oyinbo C, Fawehinmi H (2008) Prevalence of simian and Sydney creases in the Ijaws of South- South Nigeria. Internet J Biol Anthrop 3(2): 1-5.

17. Adetona MO, Oladapo 00, Akinyemi JO (2012) Palm flexion creases variants among Nigerians. Afr J Biomed Res 15(2): 93-96.

18. Taura AA, Taura MG, Adamu LH (2014) Palm Creases; A comparative study between epilepsy patients and healthy subjects among Hausas of Northern Nigeria. Am J Med and Med Sci 4(5): 175-179.

19. Alhaji MM, Timbuak J, Umana UE, Tanko M (2015) Palm creases and handedness in Hausas of northern Nigeria: a crosssectional study. Asian J Biol and Med Sci 1(2): 6-13.

20. Araoye MO (2004) Sample Size Determination in Research Methodology with Statistics for Health and Social Sciences. Nathadex Publishers, Ilorin 8(8): 115-121.

21. World Medical Association Declaration of Helsinki (2001) Ethical Principles for Medical Research Involving Human Subjects. Bulletin of the World Health Organization 79(4): 373-374.

22. Cummins H, Midlo C (1961) Finger prints, palms and soles: an introduction to dermatoglyphics. Dover Publications, New York, USA.

23. Singh S, Khurana AK, Harode HA, Tripathi A, Pakhare A, et al. (2016) Study of fingerprint patterns to evaluate the role of dermatoglyphics in early detection of bronchial asthma. J Nat Sc Biol Med 7(1): 43-46.

24. Ekanem EP, Eluwa MA, Udoaffah GU, Ekanem TB, Akpantah AO (2009) Digital Dermatoglyhics patterns of Annang Ethnic group in Akwa Ibom State of Nigeria. The International Journal of Biological Anthropology $3(1)$.

25. Jaja BN, Igbigbi PS (2008) Digital and Plamar Dermatoglyphics of the Ijaw of Southern Nigeria, Africa. Journal of Medical Science 37(1): 1-5.

26. Igbigbi PS, Didia BC, Agan TU, Ikpae BE (1995) Palmar and digital dermatoglyphic pattern in two ethnic communities in Nigeria. West Africa. Journal of Anatomy 2: 52-56.

27. Odukuma EI, Igbigbi PS (2005) Digital dermatoglyphics in students of Delta State University, Nigeria. Journal of Experimental and Clinical Anatomy 4(1): 30-32.

28. Prateek R., Keerthi RP (2010) A study of fingerprints in relation to gender and blood group. J Indian Acad Forensic Med 32(1): 11-14.

29. Odokuma EI, Igbigbi PS, Emudianughe TS (2008) A study of thumb print patterns and ABO Blood group distribution. J Exp Clin Anat 7(1): 22-26. 
30. Adamu LH, Ojo SA, Danborno B, Adebisi SS, Taura MG (2016) Sex prediction using ridge density and thickness among the Hausa ethnic group of Kano state, Nigeria, Australian Journal of Forensic Sciences p. 1.

ISSN: $2574-1241$

DOI: 10.26717/BJSTR.2020.29.004739

Anyanwu Luke Chukwumah. Biomed J Sci \& Tech Res

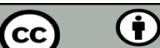

This work is licensed under Creative Commons Attribution 4.0 License

Submission Link: https://biomedres.us/submit-manuscript.php
31. Iso-Iso U, Mesembe OE, Ewunonu EO (2019) Sex variations in thumbprint ridge count of a Nigerian population in Calabar municipality. Anatomy Journal of Africa 8(2): 1544-1551.

$\begin{array}{ll}\text { BIOMEDICAL } & \text { Assets of Publishing with us } \\ \text { RESEARCHES } & \text { - Global archiving of articles } \\ \text { - Immediate, unrestricted online access } & \text { - Rigorous Peer Review Process } \\ & \text { - Authors Retain Copyrights } \\ \end{array}$

